\title{
A clinical study of maternal outcome among pregnant mothers suffering from preeclampsia with thrombocytopenia
}

\author{
Kavyashree H. S. ${ }^{1}$, Rajeshwari K. ${ }^{2 *}$
}

\begin{abstract}
${ }^{1}$ Department of Obstetrics and Gynecology, Mysore Medical College and Hospital, Mysore, Karnataka, India ${ }^{2}$ Department of Obstetrics and Gynecology, Chamarajanagara Institute of Medical Sciences, Yadapura, Karnataka, India
\end{abstract}

Received: 02 February 2019

Accepted: 09 February 2019

\author{
*Correspondence: \\ Dr. Rajeshwari K. \\ E-mail: statisticsclinic2018@gmail.com
}

Copyright: () the author(s), publisher and licensee Medip Academy. This is an open-access article distributed under the terms of the Creative Commons Attribution Non-Commercial License, which permits unrestricted non-commercial use, distribution, and reproduction in any medium, provided the original work is properly cited.

\begin{abstract}
Background: The thrombocytopenia in preeclampsia is mild to moderate, but severe thrombocytopenia can occur. Patients with eclampsia were at even greater risk for developing severe thrombocytopenia. And more likely to have HELLP syndrome, which is a subset of preeclampsia. Thrombocytopenia is a key and necessary component of this syndrome. The objective of the present study was to observe a clinical study of maternal outcome among pregnant mothers suffering from preeclampsia with thrombocytopenia.

Methods: A Hospital based Study was conducted at Mysore Medical College from January 2018 to December 20180 in the department of Obstetrics and gynecology. A total of 100 cases of Pregnancy from the records / case sheets of pregnant women with pregnancy induced hypertension admitted in the labor ward of the department of obstetrics and gynecology, Mysore Medical College, Mysore, Karnataka, India.

Results: Majority of the study subjects in present study were aged between $21-25$ years (42\%) followed by <20 years (26\%). Nearly $55 \%$ of the study group were prim parous. In the above table out of 100 cases included in the study, 28 and 40 cases presented with mild and severe pregnancy induced hypertension, 8 cases were diagnosed as eclampsia and 24 cases presented with HELLP syndrome. The association between the mode of delivery and the variants of PIH was found to be statistically not significant. The Association between Mode of delivery and gestation weeks among the eclampsia cases was found to be not significant.

Conclusions: Thrombocytopenia in pregnancy induced hypertension carries a risk for both the mother and her fetus. The associated causes like abruption, retain dead fetus, septicemia and disseminated intravascular coagulation aggravates the complication for thrombocytopenia.
\end{abstract}

Keywords: Eclampsia, Maternal outcome, PIH, Pregnancy, Thrombocytopenia

\section{INTRODUCTION}

Thrombocytopenia result from a variety of causes, ranging from benign disorders such as gestational thrombocytopenia to life threatening syndromes such as HELLP syndrome, Hemolysis, Elevated liver enzymes, low platelet count. A finding of thrombocytopenia during pregnancy poses an intriguing problem before the obstetricians. Thrombocytopenia complicating hypertensive disorders of pregnancy are responsible for approximately $20 \%$ of all cases of thrombocytopenia during pregnancy. ${ }^{1}$ Thrombocytopenia results mainly from four processes -artifactual thrombocytopenia, deficient platelet production, accelerated destruction and pooling of platelets. Which is characterized principally by bleeding from small vessels. ${ }^{2}$ Platelets play a crucial role in the pathophysiology of pre-eclampsia by promoting vascular damage and obstruction, leading to tissue 
ischemia and further damage. ${ }^{3}$ Thromboxane A2 the major product of arachidonic acid metabolism in platelets, is a potent vasoconstrictor and plateletaggregating agent.

As it has a short half-life it is normally measured as its stable hydration product, thromboxane B2. The effects of thromboxane A2 are normally counterbalanced by prostacyclin, a potent vasodilator and anti-platelet prostanoid which is the major product of arachidonic acid metabolism in vascular endothelium and which plays an important role in protecting the endothelium and limiting damage by inhibiting platelet aggregation and promoting vasodilation.

These two substances function as local hormones and are thought to be important in the control of the plateletendothelium interaction. ${ }^{4}$ There are considerable evidence implicating platelets in the pathophysiology of pre-eclampsia. The circulating platelet count is reduced, reflecting a reduced platelet life- span, and an inverse relationship between platelet count and fibrinogen and fibrin degradation products has been noted, suggesting that the reduction in platelet count is due to increased platelet consumption associated with low-grade D1C.

The platelet - specific protein B- thromboglobulin, marker of platelet activation in vivo, has been found to be increased in pregnancy induced hypertension. This correlates with proteinuria and serum creatinine and suggests a link between platelet activation with renal microvascular damage. ${ }^{5}$

The time of onset of these disorders during pregnancy and their clinical manifestations often overlap, making the diagnosis of specific disorders difficult. Thrombocytopenia carries a risk for both the mother and her fetus, associated with substantial maternal or neonatal morbidity and mortality. The objective of the present study was to observe a clinical study of maternal outcome among pregnant mothers suffering from preeclampsia with thrombocytopenia.

\section{METHODS}

A hospital based study was conducted at Mysore Medical College from January 2018 to December 20180 in the department of Obstetrics and gynecology.

A total of 100 cases of Pregnancy from the records / case sheets of pregnant women with pregnancy induced hypertension admitted in the labor ward of the Department of Obstetrics and Gynecology, Mysore Medical College, Mysore.

Details will be entered in the proforma regarding the detailed history of period of gestation, high risk factors, complications- during present and past pregnancy, like pregnancy induced hypertension, diabetes mellitus, APLA, intra uterine death, abruption, hepatitis. Past history of pregnancy induced hypertension, hypertension, diabetes mellitus and hemorrhagic disorders.

\section{Inclusion criteria}

- $\quad$ Third trimester pregnant women with BP measuring more than 140/90mmHg with thrombocytopenia.

- Pregnant women with HEELP syndrome.

- Pregnant women with diagnosed pre-eclampsia and eclampsia with thrombocytopenia.

\section{Exclusion criteria}

- Patients with established ITP disease.

- Patients with hypertensive disorder before pregnancy.

- Patients established with HIV disease.

- Patients with history of viral fever.

Pregnant women who are admitted to hospital in the third trimester with BP >140/90 will be selected according to inclusion and exclusion criteria. A written consent is taken in those who satisfy these inclusion criteria.

\section{RESULTS}

A total of 100 cases were analysed in the study. Majority of the study subjects in present study were aged between $21-25$ years $(42 \%)$ followed by $<20$ years $(26 \%) .22 \%$ of the cases were between the age group 26-30 years and $10 \%$ were aged above 30 years of age.

Nearly $56 \%$ of the study participants were from rural areas and nearly $71 \%$ of them belonged to SES class III and Above in present study. Nearly $55 \%$ of the study group were prim parous (Table 1).

Table 1: Social profile of the study participants.

\begin{tabular}{|c|c|c|c|}
\hline \multicolumn{2}{|c|}{ Social profile } & Frequency & Percentage \\
\hline \multirow{5}{*}{ Age } & $<20$ years & 26 & 26 \\
\hline & $21-25$ years & 42 & 42 \\
\hline & $26-30$ years & 22 & 22 \\
\hline & $>30$ years & 10 & 10 \\
\hline & $<20$ years & 26 & 26 \\
\hline \multirow{2}{*}{ Place } & Urban & 44 & 44 \\
\hline & Rural & 56 & 56 \\
\hline \multirow{5}{*}{ SES } & I & 12 & 12 \\
\hline & II & 17 & 17 \\
\hline & III & 39 & 39 \\
\hline & IV & 21 & 21 \\
\hline & $\mathrm{V}$ & 11 & 11 \\
\hline \multirow{2}{*}{ Gravida } & Prim gravida & 55 & 55 \\
\hline & Multigravida & 45 & 45 \\
\hline
\end{tabular}

Out of 100 cases included in the study, 28 and 40 cases presented with mild and severe pregnancy induced hypertension, 8 cases were diagnosed as eclampsia and 24 cases presented with HELLP syndrome (Table 2). 
Table 2: Etiology of thrombocytopenia.

\begin{tabular}{|l|l|l|}
\hline Etiology & No. of subjects & Percentage \\
\hline Mild PIH & 28 & 38 \\
\hline Severe PIH & 40 & 53 \\
\hline Eclampsia & 8 & 9 \\
\hline HELLP & 24 & 24 \\
\hline
\end{tabular}

Out of the 100 cases of thrombocytopenia 28 cases presented with mild PIH. Out of the total 28cases the 6 $(21.5 \%)$ of them were between the 28-34 weeks of gestation, $15(53.8 \%)$ were between $34-37$ weeks and 7 $(24.7 \%)$ were over the 37 weeks of gestation. Among the 28-34 weeks of gestation, $3(50 \%)$ had normal vaginal delivery,2(33.3\%) underwent LSCS and remaining 1 case $(16.7 \%)$ had instrumental delivery.

Nearly $9(60 \%)$ cases out of 15 in the 34-37 weeks of gestational age had vaginal delivery $4(26.7 \%)$ underwent LSCS and $2(13.3 \%)$ had instrument assisted delivery. Out of 7 cases between the gestational age greater than 37 weeks, 4(57.1\%), 1(14.4\%) and 2(22.7\%) delivered through normal vaginal, LSCS and instrumental delivery respectively (Table 3 ).

Table 3: Analysis of mode of delivery and gestational age among mild PIH patients.

\begin{tabular}{|c|c|c|c|}
\hline Gestational age & $\begin{array}{l}\text { Mode of } \\
\text { delivery }\end{array}$ & $\begin{array}{l}\text { MILD } \\
\text { PIH }\end{array}$ & Percentage \\
\hline \multirow{4}{*}{ 28-34 weeks } & ID & 1 & 16.7 \\
\hline & LSCS & 2 & 33.3 \\
\hline & VD & 3 & 50 \\
\hline & Total & 6 & 100 \\
\hline \multirow{4}{*}{ 34-37 weeks } & ID & 2 & 13.3 \\
\hline & LSCS & 4 & 26.7 \\
\hline & VD & 9 & 60 \\
\hline & Total & 15 & 100 \\
\hline \multirow{4}{*}{$>37$ weeks } & ID & 2 & 28.5 \\
\hline & LSCS & 1 & 14.4 \\
\hline & VD & 4 & 57.1 \\
\hline & Total & 7 & 100 \\
\hline
\end{tabular}

Out of the 100 cases of thrombocytopenia 40 cases presented with Severe PIH.

Out of the total 40cases the $6(15 \%)$ of them were between the 28-34 weeks of gestation, 21(52.5\%) were between 34-37 weeks and $13(32.5 \%)$ were over the 37 weeks of gestation.

Among the 28-34 weeks of gestation, 4 (66.6\%) had normal vaginal delivery $2(33.4 \%)$ underwent LSCS.

Nearly $8(38.1 \%)$ cases out of 21 in the 34-37 weeks of gestational age had vaginal delivery, $10 \quad(47.6 \%)$ underwent LSCS and 10 (47.6\%) had instrument assisted delivery. Out of 13 cases with the gestational age greater than 37 weeks, $4(30.8 \%), 7(53.8 \%)$ and $2(15.4 \%)$ delivered through normal vaginal, LSCS and instrumental delivery respectively (Table 4). Out of the 28 cases of Mild PIH, 16(57.2\%) had Normal Vaginal Delivery,5 $(17.8 \%)$ were instrumental delivery and $7(25 \%)$ underwent LSCS.

Table 4: Analysis of mode of delivery and gestational age among severe PIH patients.

\begin{tabular}{|l|l|l|l|}
\hline $\begin{array}{l}\text { Gestational } \\
\text { age }\end{array}$ & $\begin{array}{l}\text { Mode of } \\
\text { delivery }\end{array}$ & $\begin{array}{l}\text { Severe } \\
\text { PIH }\end{array}$ & Percentage \\
\hline \multirow{3}{*}{ 28-34 weeks } & ID & 0 & 0 \\
\cline { 2 - 4 } & LSCS & 2 & 33.4 \\
\cline { 2 - 4 } & VD & 4 & 66.6 \\
\cline { 2 - 4 } & Total & 6 & 100 \\
\hline \multirow{3}{*}{$34-37$ weeks } & ID & 3 & 14.3 \\
\hline & LSCS & 10 & 47.6 \\
\hline \multirow{3}{*}{$>37$ weeks } & VD & 8 & 38.1 \\
\hline & Total & 21 & 100 \\
\hline & ID & 2 & 15.4 \\
\hline & LSCS & 7 & 53.8 \\
\cline { 2 - 4 } & VD & 4 & 30.8 \\
\hline & Total & 13 & 100 \\
\hline
\end{tabular}

Out of the 40 cases of Severe PIH, 16(40\%) had normal Vaginal Delivery, 5(12.5\%) had instrument assisted delivery and $19(47.5 \%)$ were delivered through LSCS.

The association between the mode of delivery and the variants of PIH was found to be statistically not significant (Table 5). Out of the 8 cases of eclampsia with thrombocytopenia, $5(62.5 \%)$ were in the 34-37 weeks of gestation and $3(37.5 \%)$ above 37 weeks of gestation.

Table 5: Mode of delivery in mild and severe pregnancy induced hypertension with thrombocytopenia.

\begin{tabular}{|l|l|l|}
\hline Mode of delivery & Mild PIH & Severe PIH \\
\hline VD & $16(57.2 \%)$ & $16(40 \%)$ \\
\hline ID & $5(17.8 \%)$ & $5(12.5 \%)$ \\
\hline LSCS & $7(25 \%)$ & $19(47.5 \%)$ \\
\hline Total & $28(100 \%)$ & $40(100 \%)$ \\
\hline
\end{tabular}

Chi square $=3.53 \mathrm{df}=2 \mathrm{p}=0.171$

Out of 4 cases which had normal vaginal delivery, 3 (75\%) were in the 34-37 weeks of gestation and $1(25 \%)$ was above 37 weeks of gestation.

There was only one case which was delivered through the assist of instrument was in the 34-37 weeks of gestation. Among 3 cases delivered through LSCS, 1(33. \%) was in $34-37$ weeks and $2(66.7 \%)$ above 37 weeks of gestation.

The association between mode of delivery and gestation weeks among the eclampsia cases was found to be not significant (Table 6). In the group of gestational age between 28 to 34 Weeks $(n=15), 66.7 \%$ of the mothers were healthy post-delivery, $26.6 \%$ had maternal 
morbidity and maternal mortality was $6.6 \%$. The association between the mode of delivery and maternal outcome was found to be statistically insignificant in this group.

In gestation between 34 to 37 weeks( $n=54), 57.4 \%$ of the mothers were healthy post-delivery, $42.6 \%$ had maternal morbidity and maternal mortality was zero. The association between the mode of delivery and maternal outcome was found to be statistically significant in this group.

More than 37 Weeks of gestation $(n=31), 71 \%$ of the mothers were healthy post-delivery, $25.8 \%$ had maternal morbidity and maternal mortality was $3.2 \%$. The association between the mode of delivery and maternal outcome was found to be statistically insignificant in this group (Table 7).

Table 6: Analysis of mode of delivery and gestational age in eclampsia with thrombocytopenia.

\begin{tabular}{|c|c|c|c|c|}
\hline \multirow{3}{*}{ Gestational weeks } & \multicolumn{4}{|c|}{ Eclampsia } \\
\hline & \multicolumn{3}{|c|}{ Mode of delivery } & \multirow{2}{*}{ Total } \\
\hline & NVD & ID & LSCS & \\
\hline 28-34 weeks & $0(0 \%)$ & $0(0 \%)$ & $0(0 \%)$ & $0(0 \%)$ \\
\hline 34-37 weeks & $3(75 \%)$ & $1(100 \%)$ & $1(33.3 \%)$ & $5(62.5 \%)$ \\
\hline$>37$ weeks & $1(25 \%)$ & $0(0 \%)$ & $2(66.7 \%)$ & $3(37.5 \%)$ \\
\hline Total & $4(100 \%)$ & $1(100 \%)$ & $3(100 \%)$ & $8(100 \%)$ \\
\hline
\end{tabular}

Fishers exact test $=0.46 \mathrm{p}>0.05$ (not significant)

Table 7: Analysis of maternal mortality and morbidity in all cases admitted with thrombocytopenia.

\begin{tabular}{|c|c|c|c|c|c|}
\hline \multirow{2}{*}{ Gestational age } & \multirow{2}{*}{ Maternal outcome } & \multicolumn{3}{|c|}{ Mode of delivery } & \multirow{2}{*}{ Total } \\
\hline & & VD & ID & LSCS & \\
\hline \multirow{4}{*}{ 28-34 weeks } & Healthy & $5(62.5 \%)$ & $3(100 \%)$ & $2(50 \%)$ & $10(66.7 \%)$ \\
\hline & Maternal mortality & $0(0 \%)$ & $0(0 \%)$ & $1(25 \%)$ & $1(6.6 \%)$ \\
\hline & Maternal morbidity & $3(37.5 \%)$ & $0(0 \%)$ & $1(25 \%)$ & $4(26.6 \%)$ \\
\hline & Total & $8(100 \%)$ & $3(100 \%)$ & $4(100 \%)$ & $15(100 \%)$ \\
\hline \multirow{4}{*}{ 34-37 weeks } & Healthy & $20(71.4 \%)$ & $3(30 \%)$ & $8(50 \%)$ & $31(57.4 \%)$ \\
\hline & Maternal mortality & $0(0 \%)$ & $0(0 \%)$ & $0(0 \%)$ & $0(0 \%)$ \\
\hline & Maternal morbidity & $8(28.6 \%)$ & $7(70 \%)$ & $8(50 \%)$ & $23(42.6 \%)$ \\
\hline & Total & $28(100 \%)$ & $10(100 \%)$ & $16(100 \%)$ & $54(100 \%)$ \\
\hline \multirow{3}{*}{ >37 weeks } & Healthy & $9(69.3 \%)$ & $3(75 \%)$ & $10(71.4 \%)$ & $22(71 \%)$ \\
\hline & Maternal mortality & $0(0 \%)$ & $0(0 \%)$ & $1(7.1 \%)$ & $1(3.2 \%)$ \\
\hline & Maternal morbidity & $4(30.7 \%)$ & $1(25 \%)$ & $3(21.5 \%)$ & $8(25.8 \%)$ \\
\hline Total & & $13(100 \%)$ & $4(100 \%)$ & $14(100 \%)$ & $31(100 \%)$ \\
\hline
\end{tabular}

\section{DISCUSSION}

Thrombocytopenia complicating hypertensive disorders of pregnancy are approximately $10 \%$. Preeclampsia affects approximately $6 \%$ of allpregnancies. ${ }^{4}$ In present study of 100 cases of thrombocytopenia, $68 \%$ of the cases had Pregnancy induced hypertension.

In the other studies done by Robert S Egerman (7-10\%), Spellacy and associates (5\%), Cunnigham and leveno $(8.5 \%)$, Hauth et al $(5.6 \%)$ was the overall incidence of PIH. ${ }^{6-9}$ The prevalence of thrombocytopenia among the PIH was $21 \%$ in the study done by Ray JG, $21 \%$ in Bob and Burrow, $20 \%$ in John G Kelton, $28.5 \%$ in Joshi et al. ${ }^{10-13}$ HELLP syndrome is part of this spectrum of platelet consumption and coagulation activation in pregnancy. Incidence of thrombocytopenia among patients with severe PIH and eclampsia around $20 \%$. In the present study, 24\% patients had HELLP syndrome. ${ }^{14}$ The Incidence of HELLP in other studies done by Sibai B $\mathrm{K}$ and Ramadan MK was $20 \%$,Burrows $21 \%$, and Martin et al study showed it at $22 \% .{ }^{11,15,16}$ Patients with severe pre-eclampsia, eclampsia and HELLP have a significant maternal mortality which can range from $1-3 \%$ as a result of multi system organ failure. ${ }^{17}$ In present study the mortality was $2 \%$ among the HELLP. This compares with other studies done by, Burrows et al (1\%) and Sibai et al also showed at $1.1 \% .^{11,15}$

\section{CONCLUSION}

Thrombocytopenia in pregnancy induced hypertension carries a risk for both the mother and her fetus. The associated causes like abruption, retain dead fetus, 
septicemia and disseminated intravascular coagulation aggravates the complication for thrombocytopenia. Thrombocytopenia more often occurs with the early onset of pregnancy induced hypertension and carries severe morbidity to both mother and fetus. HELLP syndrome remains problematic for the obstetrics health care providers. The nonspecific signs and symptoms of this disorders early in the disease process makes the accurate diagnosis difficult and delays early treatment, which has the best prognosis for the both maternal and fetal outcome. Thrombocytopenia perse did not affect the mode of delivery.

\section{Funding: No funding sources}

Conflict of interest: None declared

Ethical approval: The study was approved by the Institutional Ethics Committee

\section{REFERENCES}

1. McCrae KR, Samuel P, Schrciber AD. Pregnancy associated Thrombo-cytopenia: pathogenesis and management blood 1992;80;2697-2714.

2. Lee GR, Frester J, Wintrobes JL. Clinical hematology Vol.2, 10 ${ }^{\text {th }}$ edition; 1999.p.1579-1582.

3. Menell JS, Bursel JB. Antenatal Management of the thrombocyto-penias. Clin Perinatol. 1994; 21(3):591614.

4. Charo IF, Kieffer N, Philips DR. Platelet membrane glycoproteins. Hemostasis and thrombin; basic principles and clinical practice, Philadelphia, PA: JB Lippincott Co.; 1994.p.489-507.

5. Greer IA, Walker JJ, Cameron AD, McLaren M, Calder AA, Forbes CD. A prospective longitudinal study of immunoreactive prostacyclin and TxA2 metabolites in normal and hypertensive pregnancy. Clin Exp Hypertens 1985; B4(2-3);167-82.

6. Robert $S$ Egerman and Baha $M$ Sibai, Clinical Obstetrics and Guynaecology Vol 42. No. 2 Page 381-9.

7. Spellacy W N, Handler A, Ferre C D. a case control study of 1253 twin pregnancies from 1982 to 1987. Perinatal data base 1990;75:198- 201.

8. Cunningham FG, Leveno KJ, Bloom SL, Hauth JC, Gilstrap III. LC, Wenstrm KD. Hypertensive disorders in pregnancy. Ch 37 In William Obstetrics. 21st ed. Mc Graw Hill Company; 2002:871-907.
9. Hauth JC, Ewell MG, Levine RJ, Esterlitz JR, Sibai B, Curet LB et al. Pregnancy Outcomes in Healthy Nulliparas Who Developed Hypertension. Obstet Gynecol. 2000;95(1):24-28.

10. Ray JG, Vermeulen MJ, Burrows EA, Burrows RF. Use of antihypertensive medications in Pregnancy and the risk of adverse perinatal outcomes: McMaster Outcome Study of Hypertension in Pregnancy 2 (MOS HIP 2). BMC Pregnancy and ChildBirth 2001;1(1):6.

11. Burrows RF, Kelton JG. Low fetal risks in pregnancies associated with idiopathic thrombocytopenic purpura. Am J Obstet Gynecol. 1990;163(4):1147-50.

12. Kenton JG. The serological investigation of patients with autoimmune thrombocytopenia. Thromb Hoemost 1995;74(1):228-33.

13. Joshi SR, Tekwani DT, Bihade A, Joshi R, Murley D. Study of coagulation profile in pregnancy induced hypertension at MIMER Medical College, Talegaon, Dabhade. MedPulse - International Medical Journal. 2015;2(1):299-302.

14. Saphier CJ, Repke JT. Haemolysis elevated liver enzymes and low platelet count (HELLP) syndrome; a review of diagnosis and management. Semen Perinatol 1998;22(2):118.

15. Sibai BM, Ramadan MK, Chari RS, Friedman SA. Pregnancies complicated HELLP syndrome subsequent pregnancy outcomes long term prognosis. Am J Obstet Gynaecol. 1995;172(1):1259.

16. Martin JN Jr, Rinehart B, May WL, Magann EF, Terrone DA, Blake PG. The spectrum of severe preeclampsia: comparative analysis by HELLP syndrome classification. Am J Obstet Gynecol 1999; 180(6):1373-84.

17. Sibai BM, Ramadan MK, Usta I, Salama M. Maternal Mortality and Morbidity in 442 Pregnancies with HELLP syndrome. Am. J. Obstet Gynecol. 1993;169(4):1000-06.

Cite this article as: Kavyashree HS, Rajeshwari K. A clinical study of maternal outcome among pregnant mothers suffering from preeclampsia with thrombocytopenia. Int J Reprod Contracept Obstet Gynecol 2019;8:887-91. 